\title{
A Cambrian fossil from the Chengjiang fauna sharing characters with gilled lobopodians and radiodontans
}

Jianni Liu ( $\sim$ liujianni@126.com )

Early Life Institute https://orcid.org/0000-0001-6326-3180

Jason A. Dunlop

Museum fur Naturkunde - Leibniz-Institut fur Evolutions- und Biodiversitatsforschung

Michael Steiner

Freie Universitat Berlin

Degan Shu

Northwest University

Research article

Keywords: Lobopodians, radiodontan, Chengjiang fauna, Cambrian

Posted Date: August 1st, 2020

DOI: https://doi.org/10.21203/rs.3.rs-47449/v1

License: (c) (i) This work is licensed under a Creative Commons Attribution 4.0 International License.

Read Full License 


\section{Abstract}

Background: Lobopodians are worm-like animals with simple legs. Probably representing a grade of organization, rather than an explicit clade, some lobopodians are thought to have given rise to both Euarthropoda and Onychophora (velvet worms). Another subset has been referred to as gilled lobopodians, and are characterized by flap-like appendages along the trunk and large, raptorial forelimbs. These animals probably include the ancestors of another important Cambrian group, the Radiodonta: large predatory or filter-feeding stem-arthropods such as Anomalocaris.

Results: Parvibellus atavusgen. et sp. nov.from the Early Cambrian Chengjiang fauna of China is a small fossil preserving a distinct cephalic region bearing a pair of lateral projections and a circular, ventral mouth. The trunk bears eleven pairs of flap-like appendages and a short pair of terminal projections. A circular ventral mouth is also seen in Radiodonta and in some gilled lobopodians. Parvibellus atavus, gilled lobopodians and radiodontans also share the character of flap-like appendages along the trunk. However, the new fossil differs from radiodontans and gilled lobopodians by its small size and the absence of enlarged and/or raptorial frontal appendages. It also differs from gilled lobopodians in lacking ventral lobopod limbs, and from radiodontans in lacking stalked eyes.

Conclusions: Parvibellus atavus expresses a unique combination of characters among Cambrian arthropods, and could be part of an early radiation of nektonic stem-Euarthropoda. Lobopodians have emerged as a diverse grade of proto-arthropods ('worms with legs'), walking on the substrate of the early Palaeozoic seas. The new fossil hints at a similarly diverse fauna of nektonic (swimming) stem-group arthropods in the Cambrian, from which gilled lobopodians and radiodontans may have evolved.

\section{Background}

Cambrian fossils offer unique insights into the early stages of animal evolution. Two groups of particular significance, both of which first appear in the Cambrian, are lobopodians and radiodontans. Lobopodians have been characterised as 'worms with legs' and are thought to include the ancestors of both the modern velvet worms (Onychophora) and probably arthropods too (Euarthropoda). For overviews see, e.g. Liu \& Dunlop [1] and Smith \&Ortega-Hernández [2], and references therein [1, 2]. A remarkable lineage belonging to the euarthropod stem-group is the Radiodonta, which is usually characterised by a ring-like mouth (or oral cone)-albeit absent in some taxa [3, 4]-a pair of large and sometimesraptorial frontal appendages, and a series of flaps along the body which are presumed to have been used for swimming [5]. Some radiodontans achieved body lengths of more than two metres [6], rendering them among the largest Early Palaeozoic animals. Based on the armature of the frontal appendages and evolutionary trends from active predation through to suspension feeding has been proposed $[7,8]$.

Other genera of Cambrian stem-group euarthropods such as Opabinia Walcott, 1912 from the Burgess Shale of Canada, and Kerygmachela Budd, 1993 and Pambdelurion Budd, 1997 from the Sirius Passet of Greenland, have been referred to as gilled lobopodians. They could represent transitional forms between 
the lobopodian grade of organisation and the radiodontans [9-12]. Here, we describe a new fossil from the Early Cambrian Chengjiang fauna of China revealing a combination of characters consistent with a lineage which may have been close to the origins of gilled lobopodians and/or radiodontans.

\section{Results}

\section{Systematic palaeontology}

Lower stem-EUARTHROPODA sensu[12]

PARVIBELLUS gen. nov.

\section{Type and only species}

Parvibellus atavus gen. et sp. nov., by monotypy.

\section{Diagnosis}

Cephalic region subcircular with paired lateral projections and a large circular ventral mouth. Cephalic region clearly differentiated from trunk, which bears eleven pairs of suboval lateral flaps generally decreasing in sized from anterior to posterior; trunk terminating in a short pair of projections.

\section{Derivation of name}

From the Latin parvus (small) and bellus (cute) in recognition of its size and engaging appearance.

Parvibellusatavusgen. etsp. nov.

(Figs. 1-2)

\section{Diagnosis}

As for the genus.

Derivation of name

From the Latin atavus (ancestor), referring to its great age and the possibility that other nektonic stemeuarthropods could have evolved from this body plan.

\section{Holotype and only known specimen}

ELI-EJ 048A/B, part and counterpart. From the Chengjiang Biota, Erjie, Haikou, Yunnan, south-western China. Early Cambrian (Series 2, Stage 3), from the Yu'anshan (Heilinpu) Formation (WutingaspisEoredlichia Zone).

Description 
Complete fossil in ventral view. Total body length $5.25 \mathrm{~mm}$. Body clearly divided into a subcircular cephalic region (length $1.18 \mathrm{~mm}$, maximum width1.38 $\mathrm{mm}$ ) and a longer trunk (length $4.07 \mathrm{~mm}$ ). Cephalic region with paired projections emerging from anterior third and directed laterally and slightly posteriorly. Lateral projections $0.51 \mathrm{~mm}$ long, basal width $0.26 \mathrm{~mm}$, tapering slightly from proximal to distal. Ventral surface of cephalic region dominated by large, circular mouth region. Mouth area consists of two circles, both composed of rings of plates; diameter of outer ring $0.6 \mathrm{~mm}$, of inner ring $0.18 \mathrm{~mm}$ (Figs. 2,4B).About ten plates in outer ring and several tiny plates in inner ring, but plates are not well preserved. Trunk width ca. $1.03 \mathrm{~mm}$, preserving hints of transverse segmentation and possible median gut trace. Trunk mostly straight, bending slightly to the left posteriorly (Fig. 1). Trunk bears eleven pairs of flap-like projections along its entire length. Individual flaps suboval to subtriangular in outline; transition from trunk to flap indistinct, but flap length ranging from ca. $0.82 \mathrm{~mm}$ to $0.27 \mathrm{~mm}$. Trunk flaps 3-4 largest, with subsequent flaps becoming successively smaller towards posterior end (Figs. 1; $4 \mathrm{~A}, \mathrm{C})$.Anterior pair of flaps separate from the rest and project more laterally. Other flaps orientated postero-laterally and overlapping slightly. Disposition of the flaps gives the entire trunk a broadly oval outline in overview; maximum preserved width of entire animal ca. $2.37 \mathrm{~mm}$. Trunk terminates in a pair of short projections (left one mostly missing), or furcae, length $0.25 \mathrm{~mm}$ (Figs. 1; 4A,C).

\section{Discussion}

The preserved morphology of Parvibellus atavus gen. et sp. nov. appears to be unique among the animals found so far at Chengjiang, and from comparable Cambrian to Ordovician Lagerstätte. In overview, the fossil is fairly small (length ca. $5 \mathrm{~mm}$ ), with a distinct cephalic region bearing a single pair of tapering lateral projections (Fig. 1). The mouth is circular, possibly formed from circlets of plates, and located ventrally in the middle of the cephalic region (Fig. 2). Any plate dentition is equivocal. There is no evidence that the lateral projections represent stalked eyes, i.e. they are not bulbous at the tips, and these same projections are neither articulated into limb podomeres nor enlarged or raptorial with either spines or setae. A sensory function as antennae seems plausible. The trunk expresses at best only weak ventral segmentation, but clearly bears eleven pairs of flap-like appendages (Fig. 1A) along its length with the flaps often overlapping slightly, especially towards the posterior end. In life these flaps probably sloped below the flap behind it, a condition also seen in, e.g., the radiodontan Anomalocaris Whiteaves, 1892 where it may have been an adaptation for swimming [5] through enabling the entire lateral body margin function as a single fin flap. In the new fossil there is no evidence for ventral leg-like appendages (i.e.lobopods) associated with these flaps. The trunk terminates in a pair of short projections.

A possible interpretation of this fossil is an early instar of a radiodontan in which the circular ventral mouth and flaps along the trunk are present, but the stalked eyes and raptorial frontal appendages have not yet developed. Arguing against this is the fact that unequivocal juvenile radiodontans such as the ca. $18 \mathrm{~mm}$ long specimen of Lyrarapax unguispinus Cong et al., 2014 described by Liu et al. [13] resemble adults (cf. [3]) and have fully developed stalked eyes and spiny frontal appendages. If the new fossil were a juvenile radiodontan, it would imply a fundamental shift in their morphology during early postembryonic development. Lobopodian affinities also appear unlikely as the fossil lacks an elongate, worm- 
like body. The closest match among the known lobopodians would be Aysheaia pedunculata Walcott, 1911 which also has laterally projecting (albeit here branching) frontal appendages and ten pairs of fairly broad lobopod limbs $[1,14]$. By contrast, the trunk appendages of our new fossil appear flap-like (Fig. 1),with a degree of overlap in life typical for a nektonic animal (see above), and are thus inconsistent with a function as walking appendages. Furthermore, none of the Early Palaeozoic lobopodians are known to have a ventral mouth [1], although it should be noted that a mouth in this position is present in modern velvet worms (Onychophora).

\section{Comparisons with gilled lobopodians and radiodontans}

The circular ventral mouth consisting of two putative rings, together with the flap-like appendages along the trunk could support affinities with radiodontans. Budd [9] recognised an 'AOPK' group comprising Anomalocaris (a radiodontan), plus the gilled lobopodians Opabinia, Pambdelurion and Kerygmachela.These taxa share the presence of lateral lobes and enlarged frontal appendages. Several subsequent studies also recovered gilled lobopodians close to Radiodonta ([7, 15]; [6]: supplementary data), Ortega-Hernández [12] noted that the gilled lobopodians probably represent a grade, rather than a clade, and that within this assemblage the position of the mouth may have shifted from an anterior position (Kerygmachela) to a ventral position (Pambdelurion, Radiodonta).

Also important are the trunk appendages. Parvibellus atavus gen. et sp. nov. reveals eleven pairs of flaps (Fig. 1A), exactly matching the count in Pambdelurion and Kerygmachela $[9,16]$ and at least some radiodontans where the complete body is known $[6,17]$. Other radiodontans have been described with eight to ten pairs of trunk flaps $[3,8,18]$, while Opabinia has fifteen. Additionally, Opabinia, Pambdelurion and Kerygmachela have all been interpreted as having both lateral flaps and lobopod limbs $[9,10]-$ hence the name gilled lobopodians- although at least in Opabinia the lobopod limbs are less obvious and have not been universally accepted [19]. Radiodontans were traditionally assumed to have lost the lobopod limbs and retained only the flaps. Van Roy et al. [6], see also [11], proposed that radiodontans actually possessed both dorsal and ventral flaps: the dorsal flaps homologous with the flaps of the gilled lobopodians, the ventral flaps homologous with their stubby lobopodian limbs. In this hypothesis these dorsal/ventral structures may eventually have evolved into the typical arthropod biramous limb ([6]: Fig. 4).

\section{Affinities of Parvibellus}

So where could Parvibellus atavus gen. et sp. nov.fit into these evolutionary scenarios? A cephalic region bearing a single pair of appendages suggests it belongs to the lower stem-Euarthropoda sensu [12].As noted above, the circular ventral mouth and eleven pairs of lateral flaps are strongly reminiscent of radiodontans, and similar flaps are also seen in gilled lobopodians. A ventral mouth is also present in Pambdelurion [20].The cephalic projections in the new fossil are primarily orientated laterally and are not demonstrably raptorial. In this sense they differ from the more anteriorly directed and spiny frontal appendages of at least Pambdelurion, Kerygmachela and the radiodontans; Opabinia, by contrast, has a 
proboscis. There is no evidence in the new fossil for stalked eyes projecting laterally as in radiodontans. Pambdelurion and Kerygmachela have been reconstructed without eyes $[9,16]$, while Opabinia has an unusual pattern of five stalked eyes on the dorsal surface. The dorsal surface of the new fossil, and any eyes it may have borne, remains equivocal. Finally, at $5 \mathrm{~mm}$ in body length the new fossil is noticeably smaller than both the gilled lobopodians (Opabinia ca. $7 \mathrm{~cm}$, Pambdelurionca. $29 \mathrm{~cm}$, Kerygmachela ca. $18 \mathrm{~cm}$ ) and the radiodontans (ca. $20 \mathrm{~cm}$ as adults up to more than 2 metres).

One solution would be to place the new fossil as sister-group to the clade encompassing the gilled lobopodians and the radiodontans: the 'AOPK' group sensu Budd [9] (Fig. 3A). This entire lineage could be defined by the acquisition of lateral flaps and, presumably, a shift from walking to swimming as the primary mode of locomotion. The gilled lobopodians and radiodontans could be further characterised by their larger body size and a probably predatory lifestyle facilitated by the development of a large, raptorial

forelimbs. The implication would be that the lateral cephalic projections in the new fossil are homologous with the radiodontan frontal appendages. The problem with this hypothesis is the apparent absence of lobopodian limbs in Parvibellus atavus gen. et sp. nov. Either lobopod limbs were present in the new fossil, but have not been preserved, or there were at least two independent losses and/or transformations (sensu Van Roy et al. [6]) of these lobopod appendages. Placing the new fossil higher in the tree as, for example, sister-group to Radiodonta (Fig. 3B), could be reconciled with only a single loss of the lobopod limbs, but would require a reversal with respect to the enlargement and modification of the frontal appendages.

\section{Conclusions}

The present material does not allow us to unequivocally resolve the phylogenetic position of Parvibellus atavus gen. et sp. nov. Further discoveries may reveal other taxa with character combinations bridging the gap between lobopodians and radiodontans, and this may help in placing the new fossil more robustly. The important message here is that there were small, swimming arthropods in the Chengjiang biota (Fig. 4) with a fairly simple grade of organisation from which other, more complex, body plans could have evolved. Just as lobopodians seem to have been a diverse grade of animals with walking appendages associated with several individual morphologies [1], so there may have been a similar nektonic grade of lower stem-group arthropods in the Early Cambrian whose diversity and relationships remain to be explored.

\section{Methods}

The new specimen was studied under a Leica steromicroscope M125and drawn with a camera lucida attachment. Both low angle light and immersion in alcohol proved useful for resolving details. Energydispersive spectroscopy (EDS) analyses of the specimen without coating were conducted on a ZEISSSupra40VP environmental scanning electron microscope with an Inca(EDS) system and X-max $50 \mathrm{~mm} 2$ detector at the FU Berlin.Brightness/contrast and the tone of all images were refined by optimizing the levels in Adobe Photoshop CC 2014. The figures were prepared with Coral Draw X7. Systematic 
terminology follows Ortega-Hernández [12]. Panarthropoda refers to a clade including Euarthropoda, Onychophora and Tardigrada. Euarthropoda sensu Lankester, 1904 consists of the clade including the most recent common ancestor of extant chelicerates, myriapods, and pancrustaceans and all of its descendants, to the exclusion of Onychophora and Tardigrada.

\section{Abbreviations}

ce: cephalic region; cm: circular mouth; flp: flap-like projections; fu: furcae; ir: inner ring; Ip: lateral projections; or: outer ring; pl: plates; tr: trunk;ts, trunk segmentations.

\section{Declarations}

\section{Acknowledgements}

We thank Prof. John Paterson, the editor, and three anonymous reviewers for their helpful comments.

\section{Funding}

This research was supported by Key Scientific and Technological Innovation Team Project in Shaanxi Province, the National Natural Science Foundation of China $(41222014,41172023,41621003$, 41102012), the 111Project and the Ministry of Education of China for Changjiang Scholars to J.L.

\section{Availability of data and materials}

The datasets supporting the conclusions of this article are included within the article. The fossils are deposited in the Early Life Institute (ELI) of the Northwest University, Xi'an, China under the repository number EJ 048A/B.

\section{Authors' contributions}

$\mathrm{JL}$ and DS collected and prepared the fossils, JL and MS took the SEM images, and JL and JAD wrote the manuscript. JL made the camera lucida drawings and photographed the specimens. All authors contributed to data interpretation and manuscript writing. All authors read and approved the final manuscript.

\section{Competing interests}

The authors declare that they have no competing interests.

\section{Author details}

${ }^{1}$ State Key Laboratory of Continental Dynamicsand Shaanxi Key Laboratory of Early Life and Environment, Department of Geology, Northwest University, Xi'an, 710069, PR China 
${ }^{2}$ Museum fürNaturkunde,Leibniz Institute for Research on Evolution and Biodiversity at the Humboldt University Berlin,D-10115 Berlin, Germany

${ }^{3}$ Department of Earth Science,FreieUniversität Berlin, D-12249, Berlin, Germany

${ }^{4}$ School of Earth Sciences and Resources, China University of Geosciences (Beijing), 100083, PR China

\section{References}

1. Liu JN, Dunlop JA.Cambrian lobopodians: A review of recent progress in our understanding of their morphology and evolution. Palaeogeography, Palaeoclimatology, Palaeoecology.2014;398:4-15.

2. Smith MR, Ortega-Hernández J. Hallucigenia's onychophoran-like claws and the case for Tactopoda. Nature. 2014;514:363-366.

3. Cong PY, Daley AC, Edgecombe GD, Hou XG, Chen AL. Morphology of the radiodontan Lyrarapax from the early Cambrian Chengjiang biota. Journal of Paleontology. 2016;90:663-671.

4. Cong PY, Edgecombe GD, Daley AC, Guo J, Pates S, Hou XG, Zhang XG. New radiodonts with gnathobase-like structures from the Cambrian Chengjiang biota and implications for the systematics of Radiodonta. Special Papers in Paleontology. 2018;4:605-621.

5. Usami Y. Theoretical study on the body form and swimming pattern of Anaomalocaris based on hydrodynamic simulation. Journal of Theoretical Biology. 2006;238:11-17.

6. Van RoyP, DaleyAC, Anomalocaridid trunk limb homology revealed by a giant filter-feeder with paired flaps. Nature. 2015;522:77-80.

7. Vinter J, Stein M, Longrich NR, Harper DAT. A suspension-feeding anomalocarid from the Early Cambrian. Nature. 2014;507,496-499.

8. Moysiuk J, Caron JB. A new hurdiid radiodont from the Burgess Shale evinces the exploitation of Cambrian infaunal food sources. Proceedings of the Royal Society B.2019;286:

9. Budd GE. The morphology and phylogenetic significance of Kerygmachela kierkegaardi Transactions of the Royal Society of Edinburgh: Earth Sciences.1999;89:249-290.

10. Budd GE, Daley AC. The lobes and lobopods of Opabinia regalis from the middle Cambrian Burgess Shale. Lethaia. 2012;45:83-95.

11. Edgecombe GD. Palaeontology: In a flap about flaps. Current Biology. 2015;25:R503-R506.

12. Ortega-Hernández J. Making sense of 'lower' and 'upper' stem-group Euarthropoda, with comments on the strict use of the name Arthropoda von Siebold, 1848. Biological Reviews. 2016;91:255-273.

13. Liu JN, Lerosey-Aubril R, Steiner M, Dunlop JA, Shu DG, Paterson JR. Origin of raptorial feeding in juvenile euarthropods revealed by a Cambrian radiodontan. National Science Review. 2018;5:863869.

14. Whittington HB. The lobopodian animal Aysheaia pedunculata Walcott, Middle Cambrian, Burgess Shale, British Columbia. Philosophical Transactions of the Royal Society of London B. 
1978;284:165-197.

15. Legg DA, Sutton MD, Edgecombe GD. Arthropod fossil data increase congruence of morphological and molecular phylogenies. Nature Communications. 2013;4:

16. Budd GE. Stem group arthropods from the Lower Cambrian Sirius Passet fauna of North Greenland. In Fortey RA\& Thomas RH. (eds)Arthropod Relationships. Chapman and Hall, London, 1997.pp. 125138.

17. Whittington HB, Briggs DEG. The largest Cambrian animal, Anomalocaris, Burgess Shale, British Columbia. Philosophical Transactions of the Royal Society of London B. 1985;309:569-609.

18. Daley AC, Budd GE, Caron JB, Edgecombe GD, Collins D. The Burgess Shale anomalocarididHurdia and its significance for early euarthropod evolution. Science. 2009;323:1597-1600.

19. ZhangXL, The nature and significance of the appendages of Opabiniafrom the Middle Cambrian Burgess Shale.Lethaia. 2007;40:161-173.

20. Vinter J, Porras L, Young FJ, Budd GE, Edgecombe GD. The mouth apparatus of the Cambrian gilled lobopodian Pambdelurion whittingtoni. Palaeontology. 2016;59:841-849.

\section{Figures}



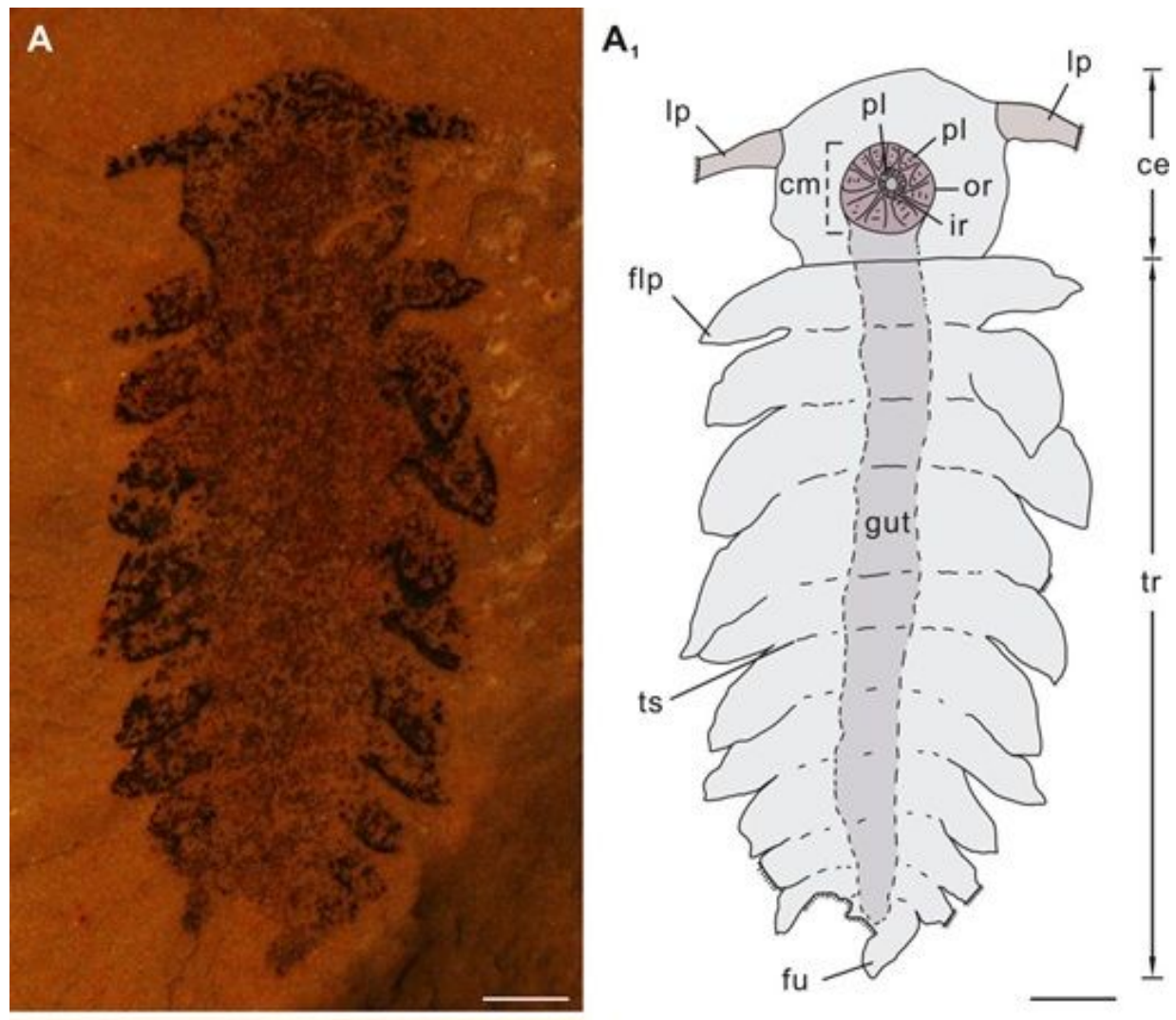

B

$\mathrm{B}_{1}$
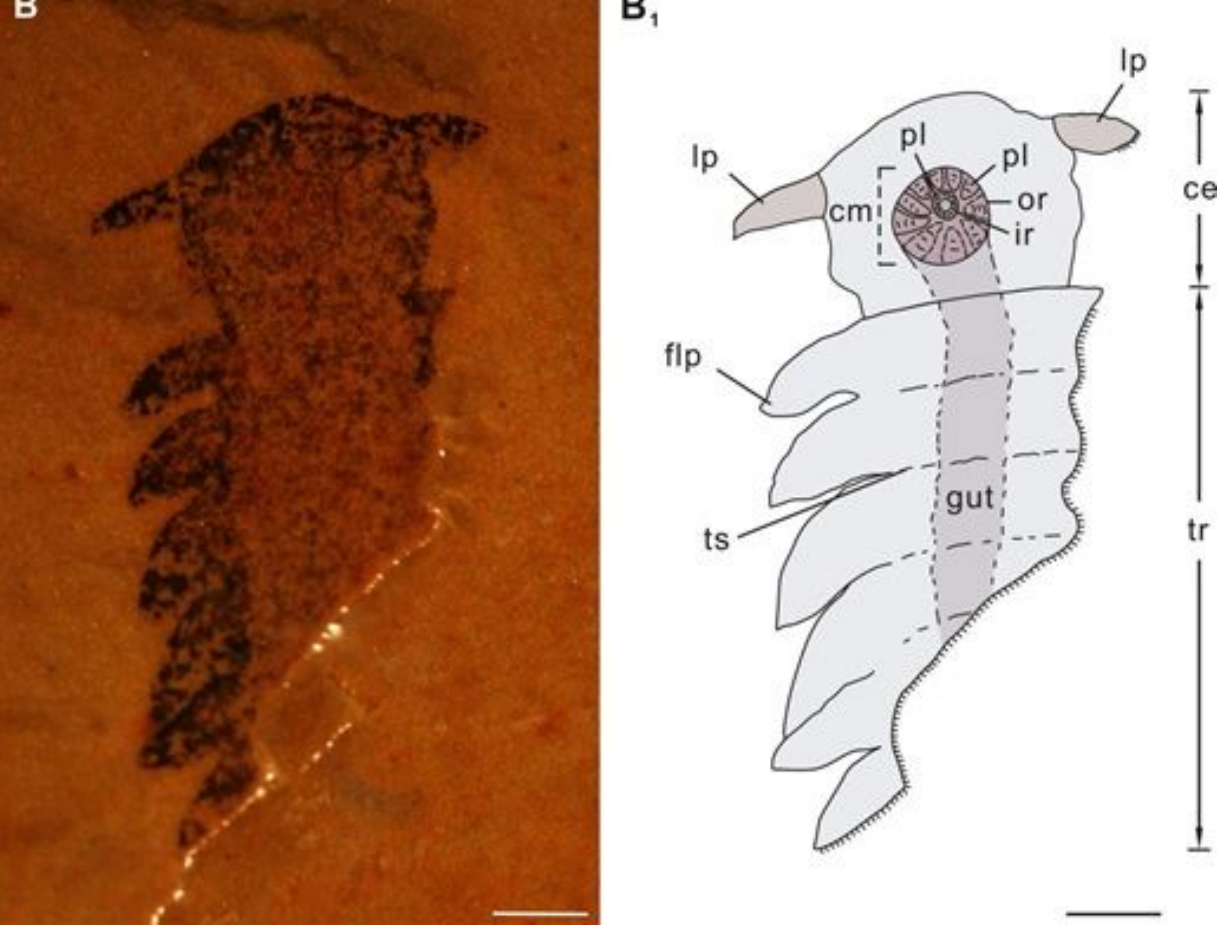

\section{Figure 1}

Parvibellus atavus gen. et sp. nov. Holotype (ELI-EJ 048A/B) and only known specimen of a new lower stem-euarthropod from the Chengjiang fauna of China preserved in ventral view, revealing a distinct cephalic region with lateral projections and a circular ventral mouth and a trunk with eleven pairs of flaplike appendages. A and A1 Part of a near-complete specimen (ELI-EJ 048) and interpretative drawing. B and B1 Counterpart (mirrored) and interpretative drawing. Scale bars0.5 mm. 

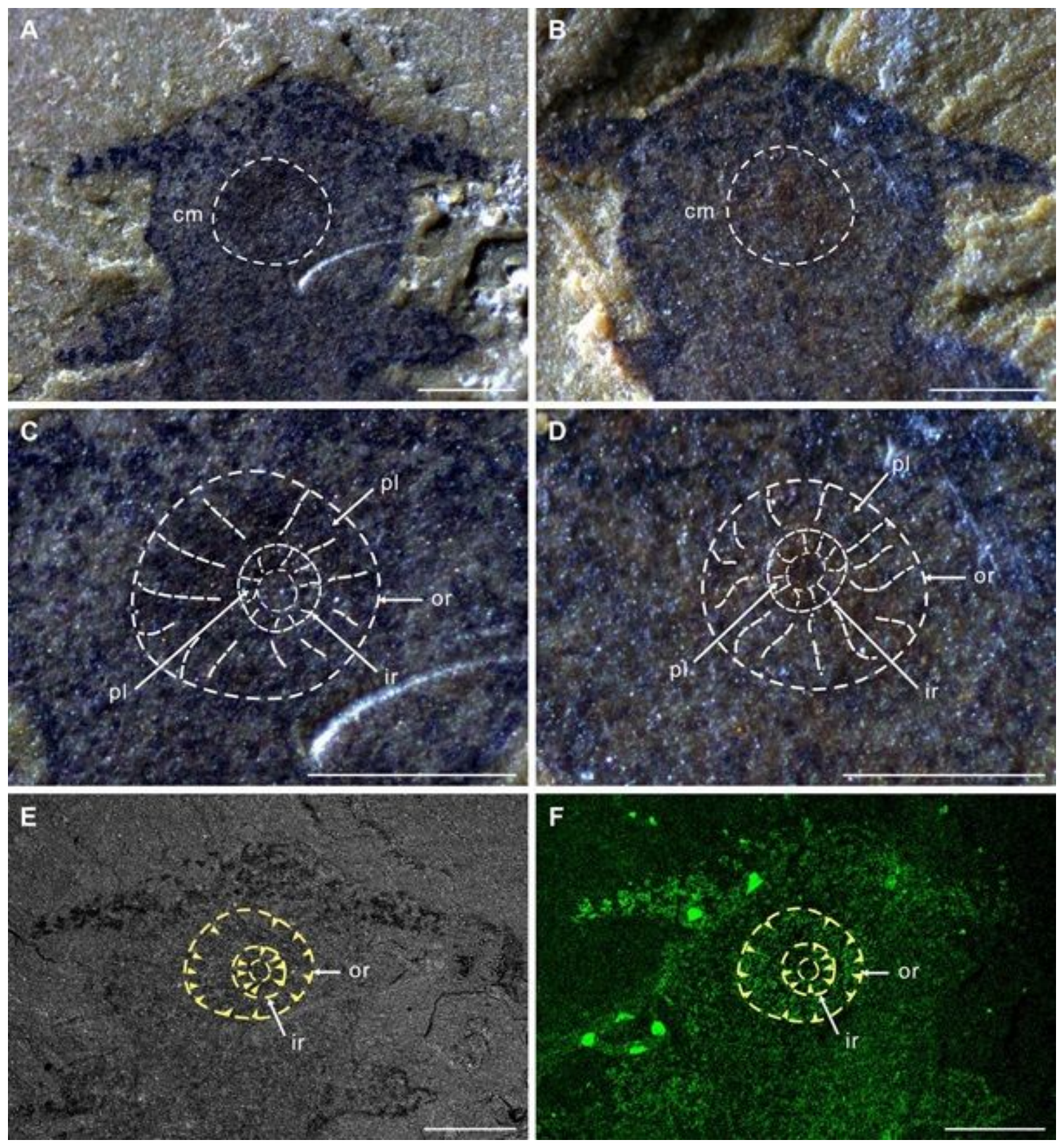

\section{Figure 2}

Enlargement of head region of Parvibellus atavus. A and B: Photographs of part and counterpart. C and D: Outlines of circlular mouth with plates. E and F: Back scattered electron micrographs and Iron element map of part, showing the outer ring (or), inner ring (ir) and plates (yellow arrowheads). Scale bar: A, B, E, F, $0.5 \mathrm{~mm} ; \mathrm{C}, \mathrm{D}, 0.1 \mathrm{~mm}$. 
A

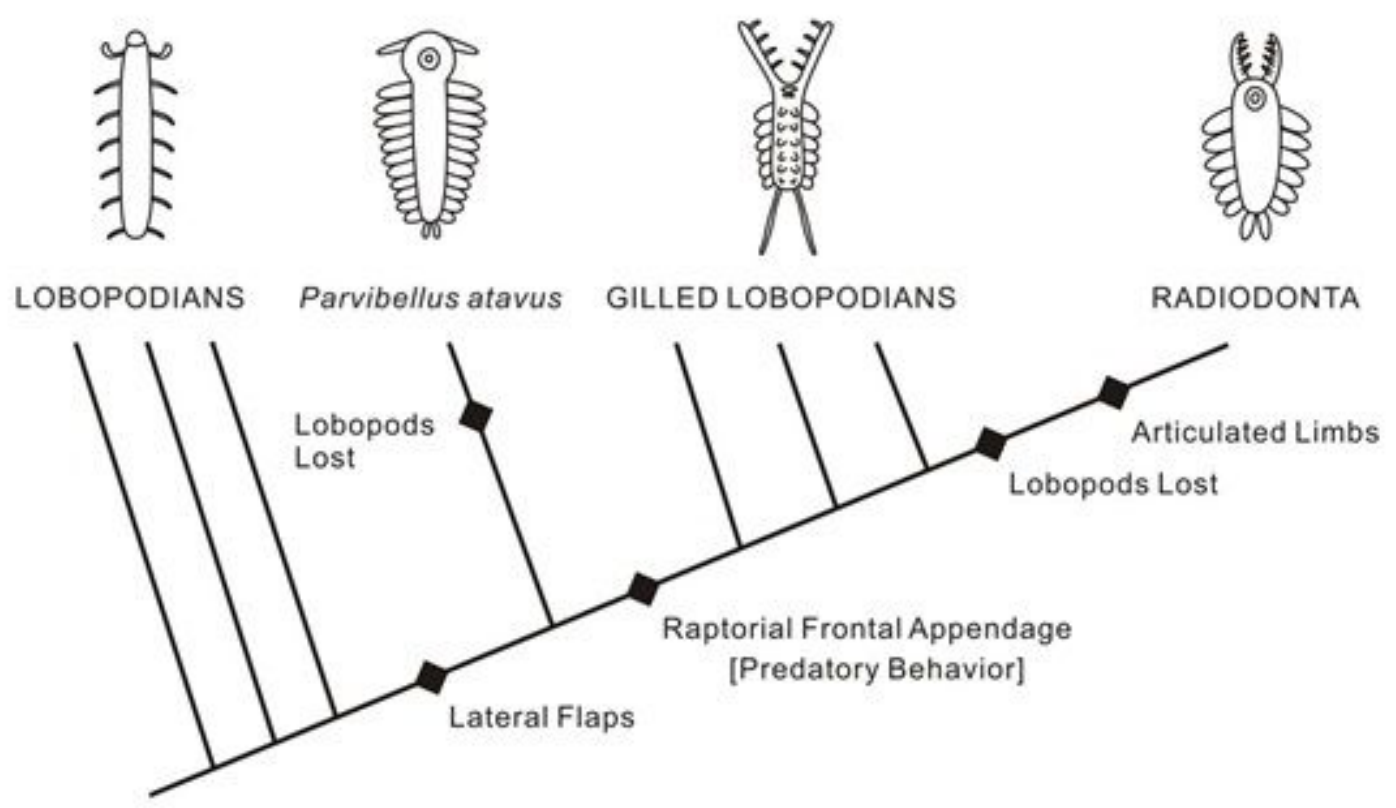

B
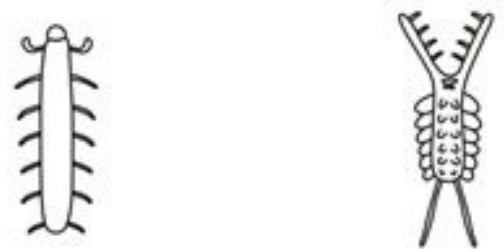

\section{LOBOPODIANS GILLED LOBOPODIANS

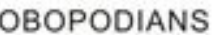

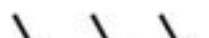
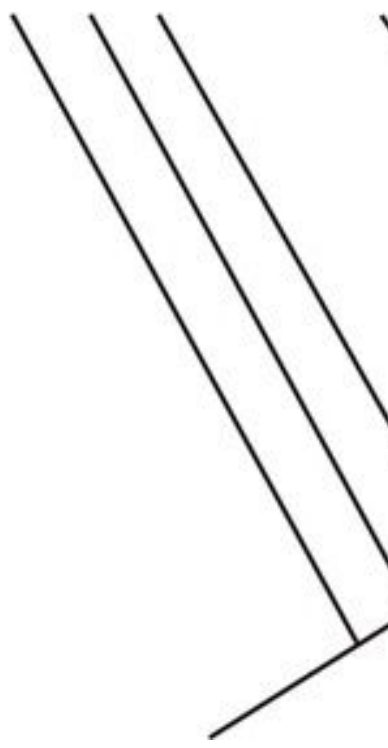
A

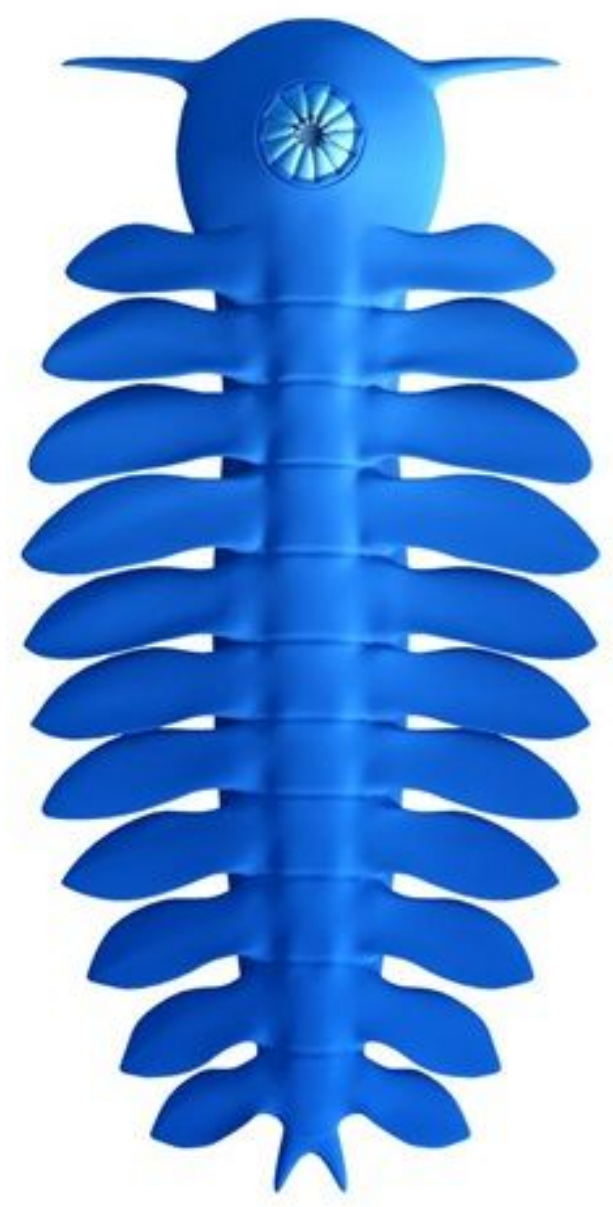

C
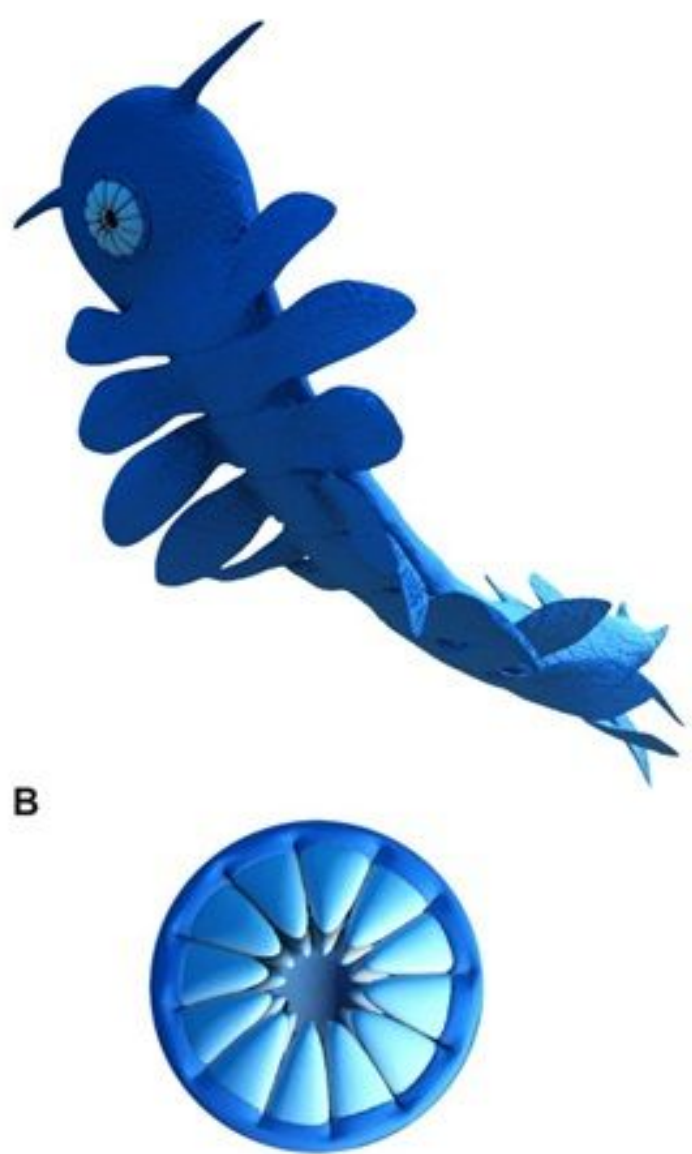

Figure 4

Reconstruction of Parvibellus atavus. A,Complete body in ventral view. B, Circular mouth with plates in ventral view, showing the out ring and inner ring. C, Artistic representation of the animal swimming in life. 